\title{
Engagement and learning in simulation: recommendations of the Simnovate Engaged Learning Domain Group
}

\author{
Wayne Choi, ${ }^{1,2}$ Ollivier Dyens, ${ }^{3}$ Teresa Chan, ${ }^{4}$ Mariles Schijven, ${ }^{5}$ Susanne Lajoie, ${ }^{6}$ \\ Mary E Mancini, ${ }^{7}$ Parvati Dev, ${ }^{8}$ Li Fellander-Tsai, ${ }^{9}$ Mathieu Ferland, ${ }^{10}$ Pamela Kato, ${ }^{11}$ \\ James Lau, ${ }^{12}$ Michael Montonaro, ${ }^{13}$ Joelle Pineau, ${ }^{14}$ Rajesh Aggarwal ${ }^{1,15}$
}

\begin{abstract}
- Additional material is published online only. To view please visit the journal online (http://dx.doi.org/10.1136/ bmjstel-2016-000177).

For numbered affiliations see end of article.

\section{Correspondence to} Dr Rajesh Aggarwal, Department of Surgery, Steinberg Centre for Simulation and Interactive Learning, Faculty of Medicine, McGill University, 3575 Parc Avenue, Suite 5640, Montreal, Quebec H2X 3P9, Canada; rajesh.aggarwal@mcgill.ca
\end{abstract}

Received 5 December 2016 Revised 2 February 2017 Accepted 7 February 2017
CrossMark

To cite: Choi W, Dyens 0 , Chan T, et al. BMJ Stel 2017;3(Suppl 1):S23-S32.

\section{ABSTRACT}

Background Health professions education (HPE) is based on deliberate learning activities and clinical immersion to achieve clinical competence. Simulation is a tool that helps bridge the knowledge-to-action gap through deliberate learning. This paper considers how to optimally engage learners in simulation activities as part of HPE.

Methods The Simnovate Engaged Learning Domain Group undertook 3 teleconferences to survey the current concepts regarding pervasive learning. Specific attention was paid to engagement in the learning process, with respect to fidelity, realism and emotions, and the use of narratives in HPE simulation.

Results This paper found that while many types of simulation exist, the current ways to categorise the types of simulation do not sufficiently describe what a particular simulation will entail. This paper introduces a novel framework to describe simulation by deconstructing a simulation activity into 3 core characteristics (scope, modality and environment). Then, the paper discusses how engagement is at the heart of the learning process, but remained an understudied phenomenon with respect to HPE simulation. Building on the first part, a conceptual framework for engaged learning in HPE simulation was derived, with potential use across all HPE methods.

Discussion The framework considers how the 3 characteristics of simulation interplay with the dimensions of fidelity (physical, conceptual and emotional), and how these can be conveyed by and articulated through beauty (as a proxy for efficiency) as coexisting factors to drive learner engagement. This framework leads to the translation of deliberately taught knowledge, skills and attitudes into clinical competence and subsequent performance.

\section{INTRODUCTION}

Education, in any form, is dependent on the engagement of the learner or student ${ }^{1}$ to be physically, mentally and emotionally involved in learning. In health professions education (HPE), the aim is for graduates to possess knowledge, exhibit skills, and demonstrate attitudes and behaviours that are paramount to providing high-quality medical care. Educational organisations such as medical and nursing schools, residency programmes, and continuing HPE, tend to define a syllabus, and focus on deliberate activities to assist in learning. ${ }^{2}$ These activities typically consist of lectures, tutorials and practical sessions delivered by an expert clinician.

Beyond such deliberate and didactic activities, arrangements with healthcare facilities allow learning in hands-on clinical settings, thus providing the experiential learning so advocated by Sir William Osler. ${ }^{3}$ This educational programme is based around clinical activity, and learning through observation, experience and gradual acquisition of knowledge, skills and behaviours. The quality of experiences and interactions may be highly dependent on the level of student-teacher interactions, the types of patient presentations encountered, and on a finely tuned elaboration of patient and disease characteristics specific to the clinical setting. Other factors, such as primacy of patient care, heavy clinical workload of tutors, the presence of multiple learners from multiple healthcare backgrounds, learner capacity and their existing knowledge, and recently, work hour restrictions, ${ }^{3}$ may interact positively or negatively on the effective engagement and outcomes of the learning process.

A pertinent example of education in the clinical setting is of the master-apprenticeship model introduced to the USA by William Halstead in the $1880 \mathrm{~s}^{45}$ following time spent observing the surgical training programme in Germany. The trainee is attached to a master surgeon and learns through observation and participation in all activities related to the patient, from the operating room, inpatient ward, surgical office and even home visits. The trainees are at the beck and call of the master surgeon (and resident at all times within the hospital) to deliver optimal care to all of their patients. It is through this process that they learn how to become master surgeons themselves. It is the master surgeon who decides when the trainee has achieved levels of performance to graduate from the programme. While this model-combined with Osler's focus on bedside learning and the transformation initiated by the Flexner Report for medical education to be more scientifically rigorous ${ }^{6}$ has served as the benchmark for over a century of postgraduate medical training across the world, the current complexity of the medical system, the increased needs and demands of patients, changing demographics, and the sheer volume of learning to acquire all suggest that may no longer be the ideal system for the education of healthcare professionals. ${ }^{7}$

Changes have been made over the past decade with regard to preclinical curricula in HPE. The 
basic science model of anatomy, biochemistry, physiology, etc, has now been replaced in the majority of medical and nursing schools with organ and disease-based blocks, corresponding to learning that is patient-based. ${ }^{8}$ Even more so, some schools cultivate the engagement of their learners with patients right from their first semester, either through intermittent encounters based on the current organ/disease block being studied, or through development of a longitudinal relationship with patients suffering from chronic diseases such as cancer, type II diabetes or heart failure, in clinical and community settings.

Despite the sea change in preclinical HPE, there has been little movement towards modernisation of teaching and learning in clinical settings. The integral role of the student as an agentic learner, comprising such characteristics as their personal epistemology, self-concept, assertiveness, resilience and self-directed learning, has not been fully realised. It is suggested that students need to be able to successfully negotiate, engage and learn from what they are afforded, in order to succeed both professionally and personally. ${ }^{9}$

A critical issue with the education of health professions is with regard to the subject material itself. Individuals seek care when they have an illness that they would like to have treated, or when they wish to maintain wellness. Understandably, they demand the best care possible to be afforded to them. But 'best', today is not limited to solely medical treatment and management; it now includes a human relationship. Therefore, HPE must be seen in a broader way: it must focus on the acquisition of medical knowledge and must also pay attention to the individual's overall wellness, from physical to mental to emotional. And while knowledge acquisition is the focus of the early stages of training, its translation into clinical skills, attitudes and behaviours is difficult to achieve. ${ }^{10}$

A bridge is thus required between knowledge acquisition and clinical practice. As previously mentioned, the apprenticeship model of training whereby the student can deliberately practise under the watchful eye of the master is the accepted paradigm. Errors may be corrected before they can lead to patient harm, ${ }^{11}$ and over time, the trainee will undertake enough experiences to be deemed competent and be certified for independent practice. ${ }^{12-14}$ While this focus on treatment may be thought of as primarily a concern in the craft specialties such as surgery, anaesthesia and gastroenterology, it may not apply as effectively

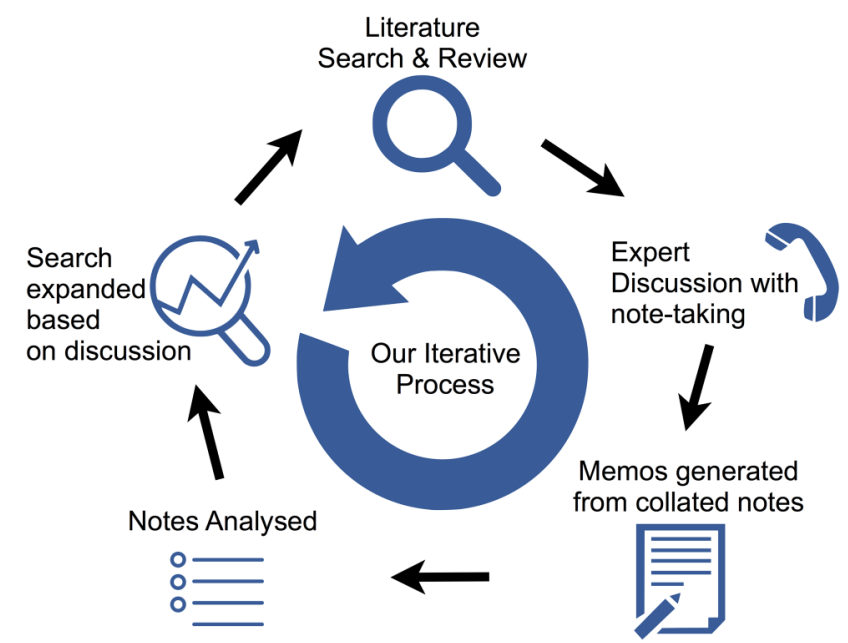

Figure 1 Iterative process for paper writing for Engaged Learning Domain Group. in clinical situations that involve interaction of a trainee with a patient or their family.

The Simnovate international summit aims to bring together experts in various fields of healthcare to shape the future of simulation, education and innovation across four domains: patient safety, pervasive learning, medical technologies and global health. This white paper represents the work of the Simnovate Engaged Learning Domain Group, which consists of an international group of experts with backgrounds in HPE, technology-enhanced learning, serious gaming, digital worlds, surgical simulation, dance and multimedia, and robotics. The group exemplifies high-level track records of educational innovation research and its implementation, through extensive publication and authority on the topic.

\section{METHODS}

We generated our white paper recommendations through a novel technique, which blended a consensus building procedure with a scoping literature review on pervasive learning, engagement in learning, motivational theories and serious games. Between September and December 2015, the members of the Simnovate Engaged Learning Domain Group convened for three teleconferences, and the members met in person in May 2016 during the Simnovate Conference.

\section{Population}

The expert working group that was assembled was recruited from an international group of individuals who had varying degrees of expertise. This group was specifically recruited to have a wide berth of expertise, from different medical specialties, medical education (undergraduate to postgraduate), serious games, simulation, gaming industry, literature and arts.

\section{Process}

Our process sought to establish: (1) the current state of engaged learning, pervasive learning and serious gaming in HPE; (2) the nature of engagement in simulation-based learning; and (3) the role of narratives in the learning process. We used an iterative, literature-informed, expert consensus-building procedure to distil the thoughts of our working group into this white paper. See figure 1 for an overview of our iterative process.

Our initial step was to gain a better understanding of the current state of serious gaming in HPE. We searched online databases such as PubMed and Google Scholar for papers that pertain to the use of games, gamification and other strategies that involved gaming elements, such as leader boards and competition in HPE, and specifically to simulation.

As the results were few, we expanded our search by including studies outside of HPE, using the same search terms. A list of suggested articles was sent to the group members prior to the first teleconference, and the topic was discussed.

Our discussions were augmented by an initial review of the literature, which were in turn, guided by the memos and notes taken during the teleconference discussions in an iterative manner. The second and third teleconferences were guided by the discussions from the previous conferences, which led to the topic of the roles of engagement and narratives in simulation for HPE. These new discussions expanded the nature of our initial literature review, necessitating two subsequent reviews of the literature to inform this conference's white paper, researching theories of engagement in learning, student engagement, cognition and emotion in learning, and motivation.

After the teleconferences, a small subset of the group (Choi, Aggarwal, Dyens, Lajoie) was tasked with coalescing the memos 
and notes from the various teleconferences, as well as integrating themes from the literature that was found. This document was then circulated within the expert group for comments and amendments both via email and in person at the Simnovate conference on 4 May 2016. The final version of this document was generated in a collaborative fashion using online collaboration tools.

\section{SIMULATION IN HPE}

Simulation can be broadly defined as 'an environment to replace or amplify real-life experiences with guided experiences that are artificially devised in order to evoke and replicate substantial elements of the real environment in an interactive, immersive and experiential manner'. ${ }^{15}$ Translated to the clinical sphere, simulation can substitute real patient encounters or other clinical situations-such as procedures and technical skills-with actors, artificial models such as mannequins and task trainers, or computers. $^{16}$

The principle for simulation in HPE is to provide an opportunity for participants to learn and to augment their clinical skills through deliberate practice, in a safe and educationally orientated environment. ${ }^{17} 18$ The aim is for these encounters to translate into the clinical setting, leading to superior performance, concomitant reduction in error and adverse events, and better patient care. Indeed, current clinical practice has an accepted concept of the learning curve, whereby performance of an individual operator gradually improves towards an asymptotic level. Patients treated by an individual or team during this learning phase are at higher risk of morbidity. This may occur without the patient's knowledge of this phenomenon or fact. High reliability industries such as nuclear, oil, armed forces and aviation extensively train and certify their employees on simulation-based models prior to real-world placements, and will often test out new approaches or tactics in the simulation setting first. ${ }^{19}$

Since its emergence in the late 1960s with the advent of 'Resusci-Anne' for resuscitation training ${ }^{20}$ and the Harvey cardiology patient simulator to reproduce heart and breath sounds, ${ }^{21}$ the evidence for simulation in healthcare has been steadily growing, especially in the past 10 years. A systematic review of technology-enhanced simulation for HPE published in $2011^{22}$ identified 609 studies comprising 35226 learners. In comparison with no intervention, simulation training was found to be consistently associated with large effects for outcomes of knowledge, skills and behaviours, and moderate effects for patient outcomes. Specific studies with regard to the impact of technical skills simulation, in the setting of central line insertion, have reported sixfold reductions in catheter-related bloodstream infections, with concomitant cost-savings of almost \$700 000 in

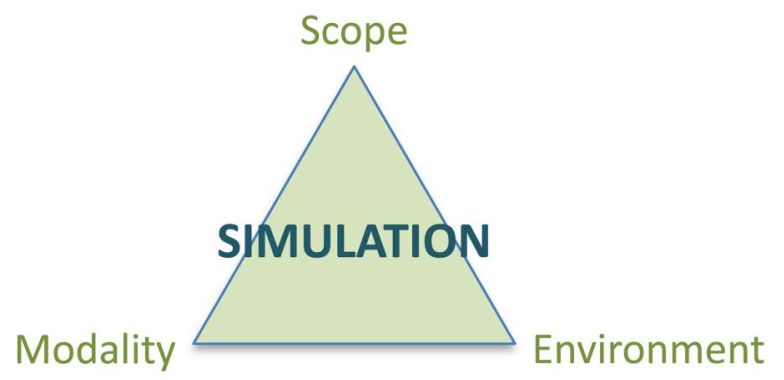

Figure 2 Novel framework for describing simulation activities using the three dimensions of simulation. a single intensive care unit. ${ }^{23} \mathrm{~A}$ medical team training programme across 74 hospital sites in the Veterans Health Administration was associated with an $18 \%$ reduction in annual mortality, compared with a $7 \%$ decrease among 34 sites that had not undergone the training programme. ${ }^{24} 25$

In addition to such convincing data, there are multiple academic societies dedicated to simulation, unprecedented federal funding, continuing advances in simulation technologies, and the proliferation of simulation centres at medical/nursing schools and teaching hospitals, it is clear that simulation has the potential and the means to revolutionise modern healthcare. In 2011, the Association of American Medical Colleges (AAMC) published a survey answered by 90 medical schools and 64 teaching hospitals, which revealed use of simulation by about $90 \%$ of medical students, and similar numbers of residents (though only in postgraduate years $1-3) .{ }^{26} \mathrm{~A}$ variety of skills have been taught through simulation, such as patient care, technical skills, communication skills and leadership. Simulation use for assessment purposes was predominantly to provide feedback, and less so for certification or assessment of competence.

\section{Describing simulation: a novel framework}

In the existing literature, types of simulation are generally categorised based on their modality, for example, standardised patients, mannequins, part or partial task trainers, or screen-based simulation. ${ }^{27-29}$ However, this method of classifying the types of simulation is not sufficient to accurately describe what any particular simulation activity will entail. This is problematic for educators since without properly recognising the different dimensions of a simulation and only considering 'mannequin or standardised patient', they are unable to fully engage the needs and requirements of the learner, and ultimately the individuals for whom they care.

We propose a novel framework to characterise simulations in three dimensions, which allows us to more accurately describe any simulation activity (figure 2):

- Scope,

- Modality,

- Environment.

\section{Scope}

The scope refers to the extent of clinical encounter involved in the simulation, which may include one or more modalities, and be set in one or more environments. What scope to choose will depend on the goals and objectives of the simulation as set by the educators, illustrated in figure 3 . Some examples of scopes are:

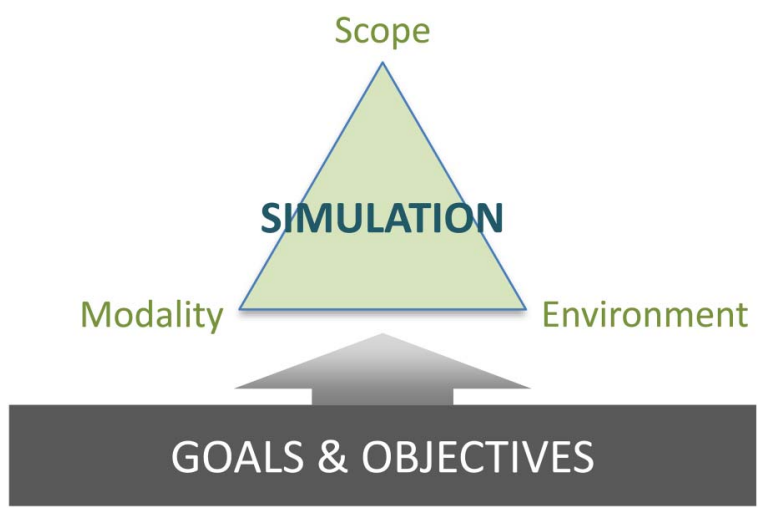

Figure 3 Goals and objectives determine the scope, modality and environment of the simulation. 


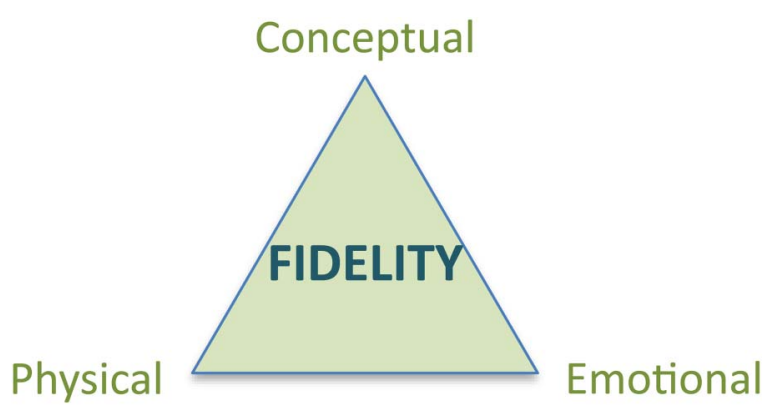

Figure 4 The three dimensions of fidelity.

- Specific task/skill: deals with a single task such as intravenous cannulation, or a specific skill such as abdominal examination;

- Partial/full procedure: a more expanded scope than a specific discrete task, and simulates more complex procedures. Often used in training of surgical procedures such as laparoscopic appendectomy on procedural trainers;

- Patient/scenario based: a simulation that entails a particular clinical scenario, such as '63-year-old man in a car accident';

- Partial/full clinical pathway: whereas the other scopes covers an episode of a short time frame (putting in an intravenous catheter, or the initial management of a car accident patient), clinical pathways span a longer time frame and have multiple steps, in multiple settings. ${ }^{30}$

\section{Modality}

Modality refers to the simulator itself, which can facilitate different scopes of simulation, and can be used in a variety of environments. Some examples of types of modality are:

- Task/procedural trainers: such as a synthetic arm for IV insertion or laparoscopic procedure trainers;

- Mannequins: a life-like mannequin to represent a patient;

- Standardised patients: trained actors to play patients;

- Computer-based/digital simulation: a modality that itself covers a wide spectrum. To list a few examples, there are applications (or 'apps') on mobile devices that provide scenario-based simulation for conceptual learning, computerbased programmes where the learner controls an avatar on screen to treat virtual patients, virtual reality immersive environments where the participant performs procedures with haptic feedback, augmented reality where digital representations overlay live objects/patients with interactions between the two worlds; ${ }^{31}$

- Mixed modality: an educator can combine multiple modalities into the same simulation. ${ }^{32}$ An example would be a scenario where the learners begin by taking the history on a standardised patient, then perform the physical examination on a mannequin that represents the same patient, and performs procedure on a task trainer or in virtual/augmented reality.

\section{Environment}

Simulations are most commonly carried out either in the same environment as the actual clinical setting, such as the ward or the operating room, or in a specialised simulation centre. Some examples of such environments are (see online supplementary appendix box 1):

- In situ: simulations done in the actual clinical environment, such as the emergency department or the operating room;
- Simulated/theatre based: this type of simulation is performed in a dedicated space for simulation, often a simulation centre. The space mimics the environment it is simulating, such as a clinical examination room or the operating room;

- Ad hoc: done in an ad hoc location such as a classroom. This provides the least amount of realism, but is offset by the fact that it is readily available;

- Virtual environments: digital simulation as a modality can offer a variety of environments. Some programmes only simulate the patient or procedure with little additional environmental details. Some systems can provide fully immersive virtual environments with which learners can interact.

\section{Realism in simulation: fidelity}

To be able to interact and learn from simulation, the simulation must behave in a realistic manner. It is important to recognise that we view reality in three ways: physical, conceptual and emotional. ${ }^{34}$ In simulation, fidelity refers to how close the simulation is to reality, and it also encompasses these three dimensions (figure 4):

- Physical fidelity: degree to which the simulation elements are sensed as approximating visual, tactile, auditory and olfactory reality;

- Conceptual fidelity: degree to which the simulation proceeds in a plausible manner;

- Emotional/experiential fidelity: degree to which the simulation generates the feelings learners would expect in a similar real situation.

These three dimensions of fidelity combine to produce a perception of realism for a learner, which may differ between learners for the same simulation. Put another way, realism is a function of the learner's perception of the simulation, rather than a property of the simulation itself, and fidelity is what simulation educators provide, through the modality and the environment, for the learners to perceive (see figure 5).

\section{ENGAGEMENT IN LEARNING What is engagement in learning?}

In 1977, Howard Bowen, an American economist and former President of the University of Iowa, published an article regarding the intended outcomes of higher education. The goals were based on "...cognitive learning, effective development, and

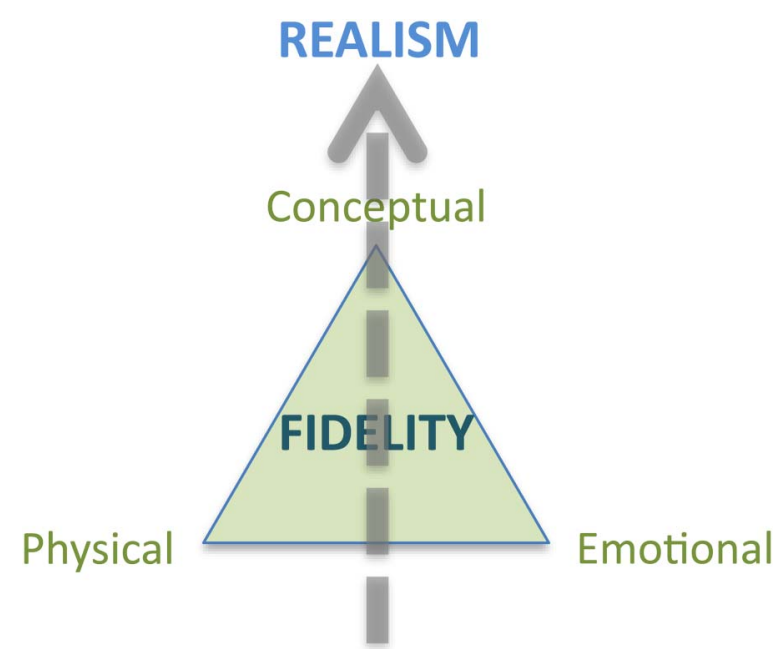

Figure 5 Dimensions of fidelity drive perception of realism. 
practical competence...[which]...may be achieved from both formal instruction and extracurricular experience." 35 In essence, educational achievement is influenced by deliberate and scheduled activities, as well as informal experiences. Faculty and students engage outside the classroom, as do the students with each other; students have different levels of motivation, and implement different learning strategies. ${ }^{36} 37$ This multifaceted array of behaviours and experiences influences student outcomes, and may be broadly described as 'engagement'.

As was stated in the introduction to this paper, engagement in learning is exceedingly important and relevant to the education of healthcare professionals. Simulation-based opportunities may be considered an ideal link between deliberate learning activities and experiential learning in the clinical setting. Optimally, healthcare simulations focus on the engagement of the learner through activities that simulate clinical situations in order to maximise students' interest, attention and learning. While thought to be physically, cognitively and emotionally engaging, the extent to which healthcare simulation embraces this role is unknown.

\section{The dimensions of engagement in learning and simulation}

In 2004, Fredricks et $a l^{38}$ offered a definition of engagement, comprising behavioural, emotional and cognitive dimensions (adapted to figure 6). Although their work focused on K-12 applications, the concept is attractive for HPE, and specifically the role of simulation.

\section{Behavioural engagement}

This considers the learners' involvement in academic activities, which may be divided into three parts: positive conduct (following rules), involvement in learning (behaviours related to concentration, attention, effort and contributing to group sessions) and participation in other related activities (administration and extracurricular).

With respect to simulation in HPE, it is critical to provide an overview of the teaching session, learning objectives and modes of assessment. It is only with this educational framework that a learner can follow rules, and be positively involved in learning through simulation. More explicitly, Rudolph et $a l^{39}$ have developed a role for presimulation briefing, in order to create a psychologically safe context for learning, a so-called 'safe container'. This enables learners to actively engage in the simulation scenario, despite the possibility of unrealistic aspects of the simulation, potential threats to their professional identity or frank discussion of mistakes, during the debriefing period. This may also be called the 'learning contract'.

Engaging in a simulated learning environment, to act as if things were real, is hard. The instructor attempts to provide sufficient fidelity in order to properly engage the learners and draw

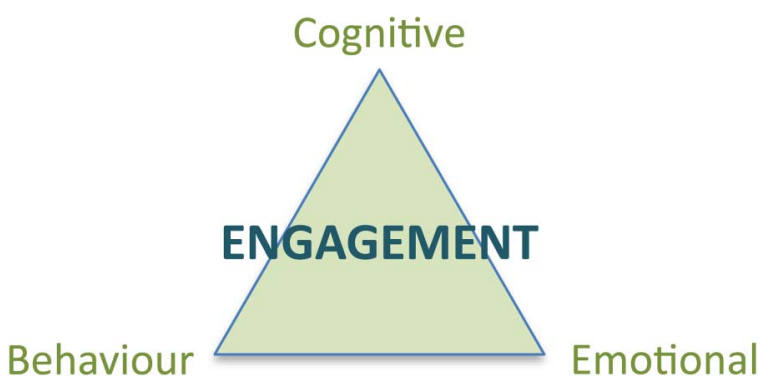

Figure 6 The three dimensions of engagement. them in: conceptual fidelity through a plausible script (or narrative), physical fidelity through appropriate modality and environment, and emotional fidelity through a combination of the other aspects. At the same time, the learners must be willing to play an active role, and as such, there is the creation of a fiction contract - an agreement to suspend disbelief and accept the presented realism of the simulation-between the instructor and each learner, and between the learners themselves. ${ }^{40}$ It is this 'fiction contract' that translates the perceived realism into behavioural engagement.

\section{Emotional engagement}

This comprises the learners' attitudes, interests and values towards learning, as well as the emotions encountered during the learning activities. Affective reactions (interest, boredom, anxiety, happiness) are those that are felt about the activity, ${ }^{41}$ and evoked emotional reactions are emotions that are evoked from the activity once a learner is already engaged (eg, an engrossing film with a strong narrative that makes the students feel sad about the characters, or a simulation scenario that leads the learner to feel stressed in a critical situation).

An example of emotional engagement is an empiric study that charted and compared the stress level and physiological arousal of senior medical students between simulated history taking encounter, a simulated breaking bad news encounter and the baseline. $^{42}$ The students' heart rates and self-reported stress levels were higher in both of the simulations when compared with the baseline, indicating heightened stress levels when they performed the activity, which suggests a heightened emotional engagement during the simulation. How may this be useful in HPE? Some research theorises that emotions-both positive and negative-can influence information retrieval. It has further been postulated that the activation of an emotion enhances the retrieval of memory that was stored in a similar state. ${ }^{43}$ We can potentially leverage simulation's ability to evoke emotions by designing simulations that will elicit the feelings that are likely to be encountered in real life, so that students will experience those emotions and encode the knowledge concurrently. Coming across similar situations later on in clinical settings, the activated emotions could potentially allow for a better retrieval of the stored knowledge.

\section{Cognitive engagement}

Fredricks et al divided this into psychological (motivational goals and self-regulated learning, relative to effortful comprehension and mastery of skills) and cognitive (metacognition and application of learning strategies) components.

Brydges and colleagues extensively reviewed the literature on self-regulated learning in simulation-based training. They defined self-regulated learning as an active learner who has developed a set of processes for managing the achievement of learning goals, and compared outcomes to those of supervised training with an instructor present. ${ }^{45}$ Unsupervised interventions were associated with poorer post-training scores. Overall, there were very few studies aimed at clarifying how trainees' self-regulatory processes can be supported in simulation. The lead author states in an earlier published article that "...it is imperative to stop equating 'self-regulation' with 'learning on one's own'." ${ }^{66}$ It is essential to create the conditions to support self-regulated learning, such as a self-guided curriculum, opportunities to use other resources (eg, videos, demonstrations, written descriptions), and appropriate feedback and debriefing. Understanding students' motivations (including long-term career 
aspirations) and providing related rationale also helps support learners to self-regulate effectively.

An example that ties in emotional and cognitive engagement would be a procedural skills simulation using a virtual reality laparoscopic simulator by a surgical resident. There are multiple tasks, levels and difficulty settings within the simulator and it can be confusing for the learner in terms of understanding their own acquisition and progression of laparoscopic skills. Without benchmark levels of skill to achieve the learner has no idea when to proceed to the next level of difficulty or task, potentially causing frustration and reducing motivation. The development of a proficiency-based virtual reality laparoscopic simulator curriculum, designed in a stepwise fashion, with predefined benchmark scores (derived from the performance of experienced laparoscopic surgeons) at each level provides appropriate increasing degree of challenge for the learner, making the activity more interesting, leading to sustained attention and effort. This supports the learner's innate drive for mastery by providing feedback of their advancing performance through deliberate practice. Furthermore, if this educational activity was presented prior to initiation of clinical training in laparoscopic procedures, it could offer additional motivation (eg, the learner sees this as a stepping stone to becoming a great surgeon, or to ensure he/she is proficient before training on real clinical situations).

\section{A FRAMEWORK FOR ENGAGED LEARNING IN SIMULATION IN HPE}

The concept of immersive educational engagement thus means creating simulation encounters that possess physical, emotional and conceptual fidelity. Simulations must also build effective narratives, which can bring the simulation encounter closer to the complexity of the real world, leading to better learner engagement. Not only would such simulations be better for teaching the procedural and technical aspects of healthcare but, through better engagement, may increase the learner's ability to care, empathise and comfort their patients. So, how do we do this?

The fundamental aspect of any educational activity is to acquire knowledge, skills and attitudes, and translate them into acceptable performance. As mentioned, in HPE, this is currently performed through a milieu of deliberate activities, and clinical immersion of variable frequency and intensity. In order for HPE, with specific regard to simulation, to have an impact on clinical performance, it is clear that the learner, faculty member and all other participants must be engaged in the activity, ideally to the same level of engagement that would occur in the clinical setting. This is dependent on the three dimensions already mentioned (cognition, behaviour and emotion) which are all mediated by the learner's response and interaction with the simulation activity. The learner's engagement is also impacted by the degree of perceived realism of the simulation-based exercise, which is a function of the level of simulation fidelity. As previously discussed, the fidelity of a simulation event can be broadly described in physical, emotional and conceptual terms, though to be more specific to simulation-based learning, would be ascribed to the modality or tools used, the environment in which they are used, and the scope and conceptual map (or pathway) of the simulation.

For example, a nursing educator wishes to teach nursing students how to manage a patient in the postanaesthesia care unit (PACU). The required knowledge, skills and attitudes may be mapped from the syllabus of the training programme, and simulation can be used to translate these activities into performance in the clinical setting. To begin with, the educational goals and objectives of the activity need to be defined (ie, managing a deteriorating patient postcardiac transplant in the PACU), which leads to the determination of the scope of the simulation (ie, a scenario-based simulation that looks at the entire patient, and not only at a specific procedure). Then, the different dimensions of fidelity need to be considered (physical, conceptual and emotional). The educator determines how 'real' the three dimensions need to help the learners achieve the goals and objectives (eg, high conceptual, moderate physical and moderate emotional). This specification then helps to prescribe how to achieve the target levels of fidelity: what modality (ie, high-feature/lowfeature mannequin, or perhaps computer), what environment (ie, in situ, or a simulated PACU setting) are needed. A more detailed narrative can then be formed, filling in the details regarding the patient scenario, case notes, vital signs, emotional tone. It is the coalescence of the physical, emotional and conceptual fidelities that lead to the perception of realism by the learner. An important point to note here is that the degree of fidelity is not directly proportional to the degree of realism; indeed low-physical fidelity mannequins and environments can be perceived to be exceedingly realistic if the conceptual and emotional fidelities are high.

Once adequate realism is achieved, it is a function of the learner, the educator and other members of the team to translate this into an engaging experience. As mentioned earlier, Rudolph et al considered this as the fiction contract, though we would caution with the exclusive use of this concept, as it tends to propose a single transaction with regard to engagement. The engagement with the simulation is an ongoing process, which begins at presimulation, during the initial brief, right through to the exercise, and its debrief. Optimal engagement occurs when (1) educators deliberately integrate the knowledge, skills, attitudes and motivations of the learners when creating and facilitating the simulation, and when (2) the fidelity of the simulation is sufficient to allow the learner to suspend disbelief to fully engage in the learning activity, which leads to the desired level of clinical performance. Figure 7 encapsulates the concepts described: realism is a product of the dimensions of simulation and fidelity, which is a necessary component for learner engagement.

\section{How to engage optimally?}

Unfortunately, our current HPE system is often not conducive to this translation of knowledge, skills and attitudes into performance. Why is that? We will forward a hypothesis: deficit in learners' engagement often relates to the system's inability to tap into emotional triggers generated by our evolutionary past and needs. The evolutionary sieve of the past 200000 years has carved our physiology to respond to tools, methods, cognitive strategies and behaviour that are conducive to an enhanced survival. We play, we play act, we invent and we convert survival clues into easily shared and emotionally charged symbols to enhance the group's survival (and thus our own). This is generally referred to as art. ${ }^{47}$

Art embodies the clues and apprenticeship necessary for our survival. ${ }^{48} 49$ Using art, we constantly generate what could be called a theatre of survival and learning in which we develop engaging techniques, devices and procedures that allow us to enhance survival, as well as experience and resolve difficult, unusual and threatening situations. Music transcends cultures and eras, for example, because of its ability to solidify the group's cohesiveness; ${ }^{50} 51$ narratives are ubiquitous for they allow us to simulate, disentangle and resolve unusual and 


\section{SIMULATION}

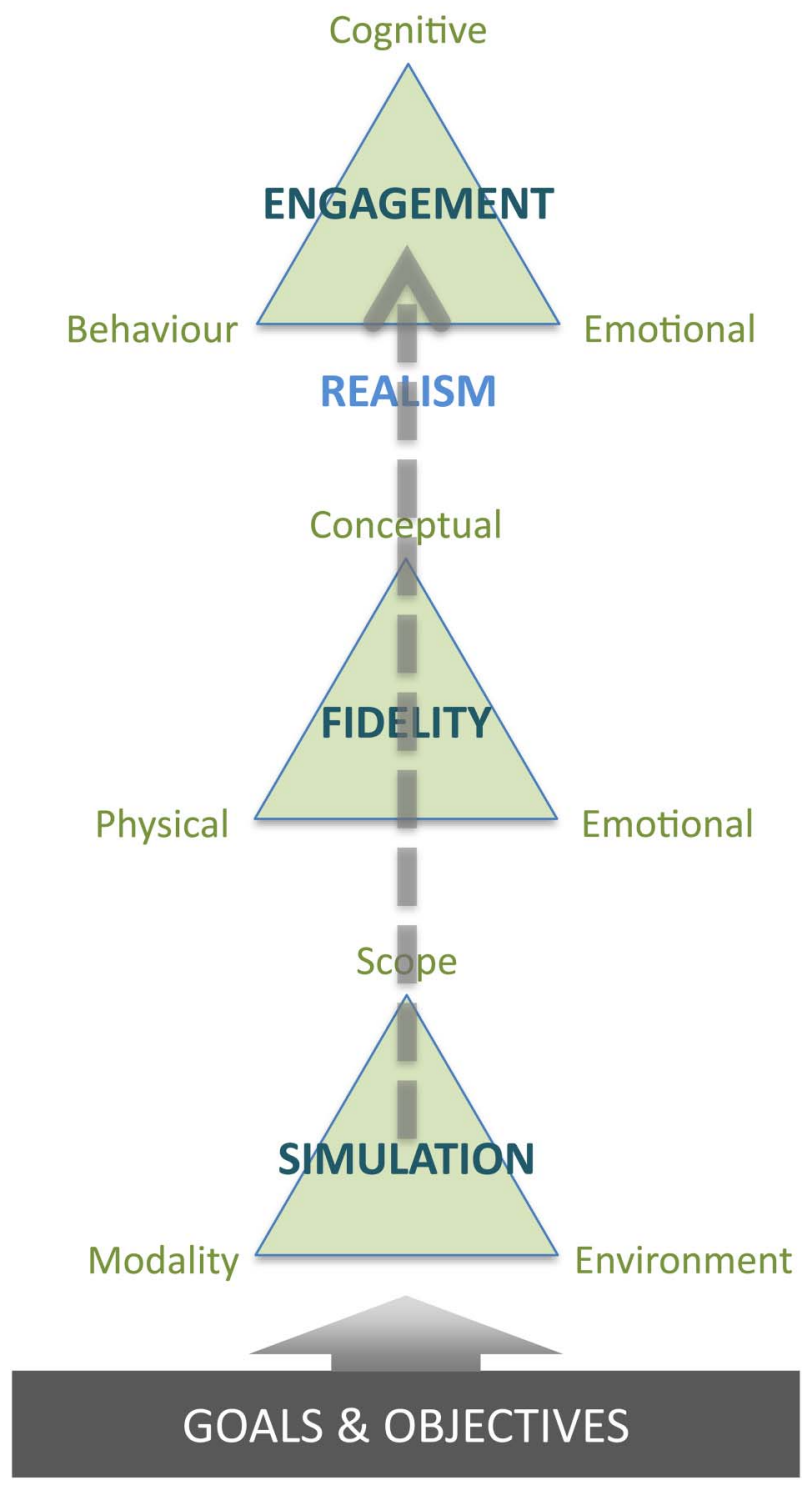

Figure 7 Engagement in simulation as a product of the dimensions of simulation and fidelity.

challenging social situations (as demonstrated by standardised patient simulations); ${ }^{52}$ paintings points to visual evolutionary clues related to reproduction (such as symmetry) $;^{53}$ dance highlights one's mastery of difficult and complex movements (generally referred to as gracefulness), and digital art points to clues on how to navigate a complex and technologically layered world.

Art embodies effective evolutionary tactics. ${ }^{54}$ Through the millennia, these tactics have evolved into highly efficient and easily combined symbolised forms, practices and rituals, so effectual in fact that the best ones trigger pleasurable physiological responses. Our hypothesis is that we have labelled these evolutionary-based responses as beauty.

If we are to truly engage learners in such difficult assignments as understanding and responding effectively to simulated medical challenges, we must recognise that the evolution carved survival mechanism we call beauty is as important in the creation and development of simulations, as the actual medical information and material we want the learner to acquire.
Beauty, we believe, is a proxy for emotional and cognitive engagement; beauty is evidence that the limbic system has been activated; beauty is the conduit to a better, more effective, longer lasting learning development; beauty is a key construct of fidelity.

What does it mean, then, in terms of medical simulations? It means creating simulations that allow the learner to develop his or her medical skills, knowledge and abilities by searching for, discovering and experiencing visual, auditory, and cognitive evolutionary clues, paths and tactics. It means creating simulations that focus on the actual medical task to be completed, and on how to best physically, cognitively and aesthetically engage in solving that task. It means, more specifically, that we should ask, as a dancer would, what are the best, most productive, most efficient and most graceful movements one should use to solve a simulated medical task and challenge? That we should wonder, as a musician would, what is the most melodious auditory environment one can create to enhance learning of a medical ability? That we should wonder, as Picasso did when he painted Guernica, what is the most engaging visual representation one can produce to rationalise complex problems or situations (war in his case; medical knowledge in ours) into clear, emotionally engaging, information rich forms?

Only when we integrate the concepts of beauty and aesthetics into health professions simulation education can we truly, optimally engage our learners (figure 8).

\section{Engaged learning in simulation: the future}

As technology continues to advance, simulations-especially computer and virtual simulations-will become more than just screen based. As such, it is ever more important to incorporate visual, auditory and tactile elements when creating simulations so that we can generate truly aesthetic fidelity (remembering that aesthetically engaging means not just 'nice' or 'pleasant' but a compelling narrative and evolutionary-based triggers), in order to fully engage the learners.

Consider how our framework may be used for the development of a serious game or virtual world learning experience. The concepts are similar, such that the syllabus will determine the baseline knowledge, skills and attitudes, and the clinical need will define the level of performance to be achieved. The digital nature of this modality-for example, virtual realitywill allow us to consider, and create, aesthetically engaging physical and emotional environments (through the digital rendering of sight, sound and touch) that are key to an engaged learning experience. Given the digital foundation of this technology, expansive scopes can be more easily done, such as a mass disaster event with casualties needing to be airlifted (which would be difficult in a non-virtual setting). The conceptual and emotional fidelity of the simulation will depend on a plausible script that covers all actors and events within the scenario, and all sequence and consequences of actions performed by the learners. Taking all of this, as well as accounting for the skills, attitudes and motivations of the learners when developing the simulation, will create an optimally engaging simulation, where aesthetics will further amplify the behavioural, emotional and cognitive engagement.

\section{Optimal engagement: beyond simulation}

Engagement in learning is vital not only in simulation, but in all other instructional methods in HPE, such as classroom, apprenticeship and informal encounters. With engagement as the goal, we can expand on the described framework on how to optimally engage learners, and apply it for the other methods. The 


\section{Simnovate supplement}

Figure 8 Framework for optimal engagement in simulation.

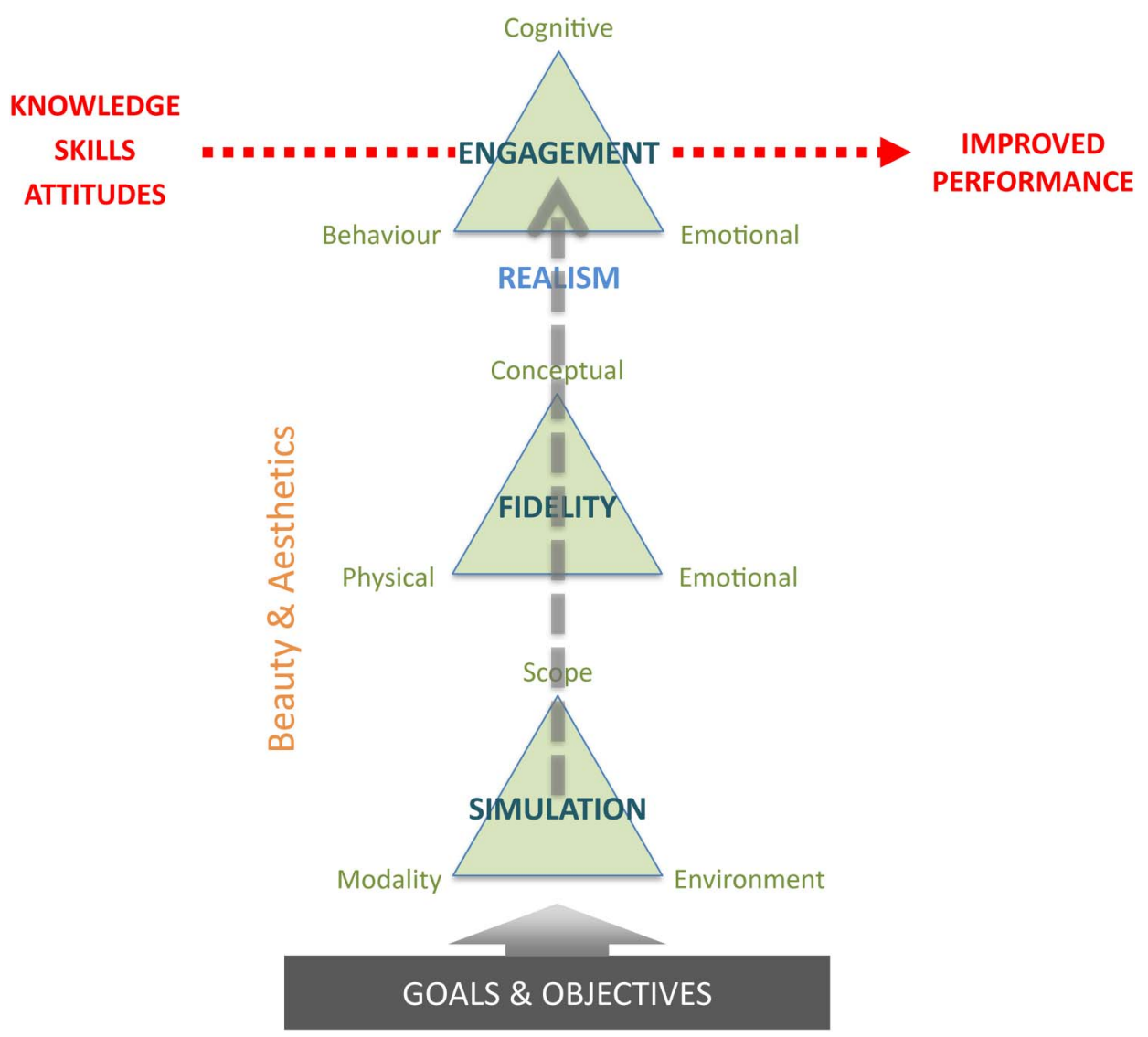

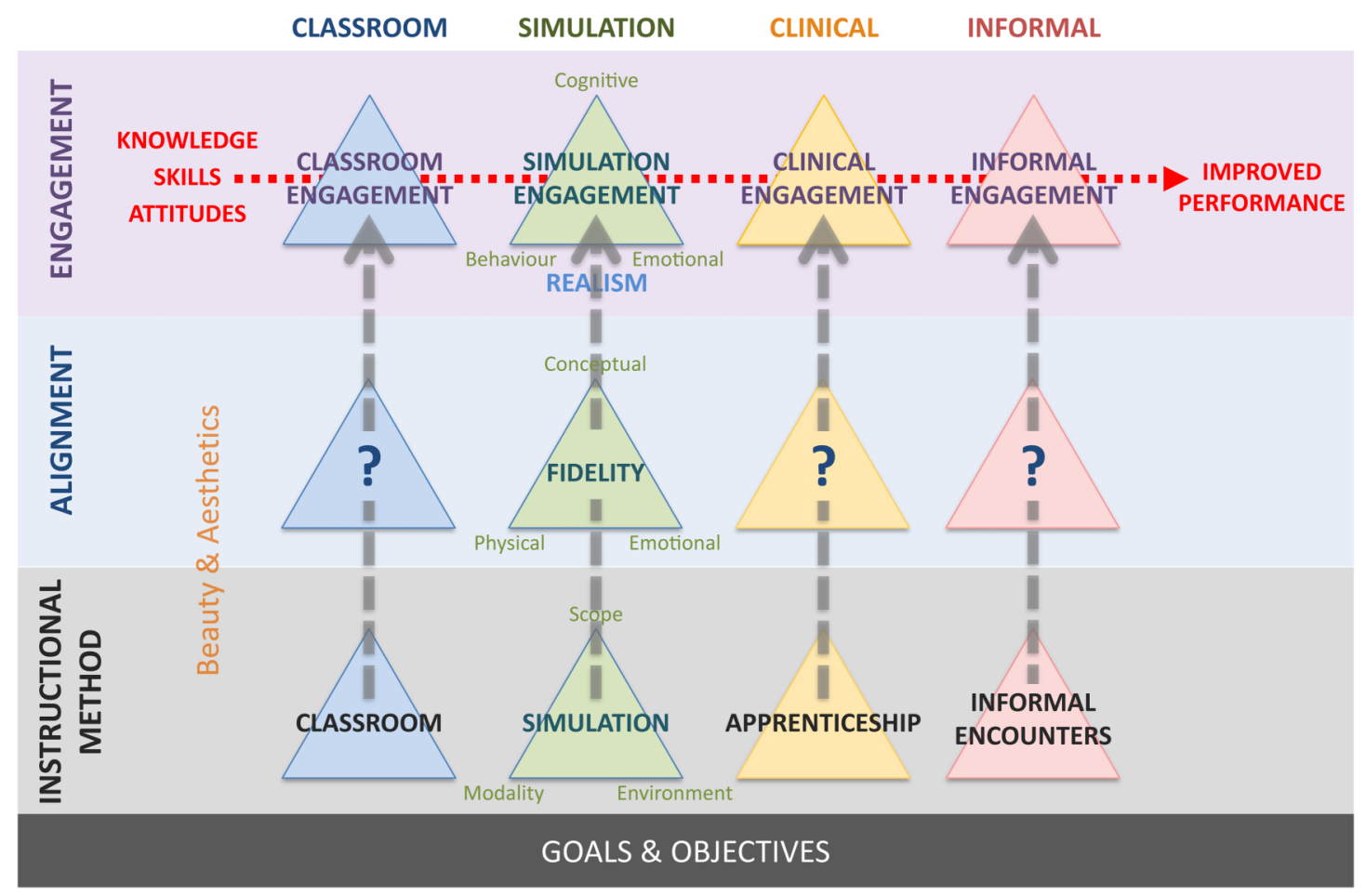

Figure 9 Model for optimal engagement in learning across instructional methods in health professions education.

key is in distilling each instructional method to its core essence, its alignment-'fidelity' in simulation-and identifying the dimensions that drives it-'conceptual, physical, emotional' (see figure 9).

\section{CONCLUDING REMARKS}

This white paper presents an overview of the current status and recommends future directions to improve engagement in healthcare simulation, through the development of a conceptual 
framework which may be applied to all forms of simulation activities. The first part of the framework provides a novel approach to describing the types of simulation by deconstructing a simulation activity into three core components (scope, modality and environment). Through these components, the educator delivers the three dimensions of fidelity (physical, conceptual and emotional) for learners to perceive. This perception of realism by the learner helps to achieve engagement (behavioural, emotional and cognitive), in order to translate deliberately taught knowledge, skills and attitudes into clinical competence and performance. There is additional focus on the role of aesthetics, serious gaming and virtual worlds, which may enable closer assimilation to real-world experiences. The drive forward is to use the suggestions and discussions outlined in this paper, to implement collaborative and systematic efforts to positively impact the level of engagement in healthcare simulation. Doing so, we believe, will ultimately enhance the quality of healthcare education and thus healthcare outcomes.

\section{Author affiliations}

${ }^{1}$ Steinberg Centre for Simulation and Interactive Learning, Faculty of Medicine, McGill University, Montreal, Quebec, Canada

${ }^{2}$ Faculty of Medicine, Department of Emergency Medicine, McGill University, Montreal, Quebec, Canada

${ }^{3}$ McGill University, Montreal, Quebec, Canada

${ }^{4}$ Division of Emergency Medicine, McMaster University, Hamilton, Ontario, Canada ${ }^{5}$ Department of Surgery, Academic Medical Centre of Amsterdam, The Netherlands ${ }^{6}$ Department of Educational and Counselling Psychology, McGill University, Montreal, Quebec, Canada

${ }^{7}$ The University of Texas at Arlington College of Nursing and Health Innovation, Arlington, Texas, USA

${ }^{8}$ Innovation in Learning, Los Altos Hills, California, USA

${ }^{9}$ Department of Orthopaedic Surgery, Karolinska University, Stockholm, Sweden

${ }^{10}$ Ubisoft Inc, Montreal, Quebec, Canada

${ }^{11}$ Serious Games Institute, University of Coventry, Coventry, UK

${ }^{12}$ Department of Surgery, Stanford University, Stanford, California, USA

${ }^{13}$ Department of Contemporary Dance, Concordia University, Montreal, Quebec,

Canada

${ }^{14}$ School of Computing Science, McGill University, Montreal, Quebec, Canada

${ }^{15}$ Department of Surgery, Faculty of Medicine, McGill University, Montreal, Quebec, Canada

Funding This research was funded through an unrestricted donation from the Blema and Arnold Steinberg Foundation.

Twitter Follow Wayne Choi @WCmed, Teresa Chan @TChanMD, Marlies Schijven @marliesschijven and Rajesh Aggarwal @docaggarwal

Competing interests RA is a consultant for Applied Medical.

Provenance and peer review Commissioned; externally peer reviewed.

\section{REFERENCES}

1 Shulman LS. Making differences: a table of learning. Change 2002;34:36-44.

2 Kern DE. Curriculum development for medical education: a six-step approach. JHU Press, 1998.

3 Dornan T. Osler, Flexner, apprenticeship and 'the new medical education. J $R$ Soc Med 2005;98:91-5.

4 Halsted WS. The training of the surgeon, Bull. Johns Hopkins Hospital, Baltimore, vol. xv, 1904, pp. 267-75

5 Hammond J. Simulation in critical care and trauma education and training. Curr Opin Crit Care 2004:10:325-9.

6 Flexner A. Medical education in the United States and Canada. Bull World Health Organ 2002;80:594-602.

7 Nguyen L, Brunicardi FC, DiBardino DJ, et al. Education of the modern surgical resident: novel approaches to learning in the era of the 80 -hour workweek. World J Surg 2006;30:1120-7.

8 Barrows HS, Tamblyn RM. Problem-based learning: an approach to medical education. Springer Publishing Company, 1980

9 Richards J, Sweet LP, Billett S. Preparing medical students as agentic learners through enhancing student engagement in clinical education. Asia-Pacific Journal of Cooperative Education, 2013;14:251-63.

10 Tainter $C R$, Wong NL, Bittner EA. Innovative strategies in critical care education. J Crit Care 2015;30:550-6.
11 Dominguez RA, Tumani PM, Prat CR, et al. Minimum frequency of simulation sessions to acquire cross skills in medical students. Poster presentation at Association for Medical Education in Europe (AMEE); Milan, Italy, August 2014.

12 Ericsson KA, Krampe RT, Tesch-Römer $C$. The role of deliberate practice in the acquisition of expert performance. Psychol Rev 1993;100:363.

13 Ericsson KA. Deliberate practice and the acquisition and maintenance of expert performance in medicine and related domains. Acad Med 2004;79:570-81.

14 Ericsson KA. Deliberate practice and acquisition of expert performance: a general overview. Acad Emerg Med 2008;15:988-94.

15 Gaba DM. The future vision of simulation in health care. Qual Saf Health Care 2004;13(suppl 1):i2-10.

16 Okuda Y, Bryson EO, DeMaria $\mathrm{S}$, et al. The utility of simulation in medical education: what is the evidence? Mt Sinai J Med 2009;76:330-43.

17 Aggarwal R, Mytton OT, Derbrew M, et al. Training and simulation for patient safety. Qual Saf Health Care 2010;19(Suppl 2):i34-43.

18 Motola I, Devine LA, Chung HS, et al. Simulation in healthcare education: a best evidence practical guide. AMEE Guide No. 82. Med Teach 2013;35:e1511-30.

19 Scalese RJ, Obeso VT, Issenberg SB. Simulation technology for skills training and competency assessment in medical education. J Gen Intern Med 2008;23:46-9.

20 Bradley P. The history of simulation in medical education and possible future directions. Med Educ 2006:40:254-62.

21 Levine Al, DeMaria S Jr, Schwartz AD, Sim AJ, eds. The comprehensive textbook of healthcare simulation. Springer Science \& Business Media, 2013.

22 Cook DA, Hatala R, Brydges $R$, et al. Technology-enhanced simulation for health professions education: a systematic review and meta-analysis. JAMA 2011;306:978-88.

23 Cohen ER, Feinglass J, Barsuk JH, et al. Cost savings from reduced catheter-related bloodstream infection after simulation-based education for residents in a medical intensive care unit. Simul Healthc 2010;5:98-102.

24 Neily J, Mills PD, Young-Xu Y, et al. Association between implementation of a medical team training program and surgical mortality. JAMA 2010;304:1693-700.

25 Neily J, Mills PD, Mazzia LM, et al. Lessons from the VA's Team Training Program. Patient Safety Network, Agency for Healthcare Research and Quality, November 2011. https://psnet.ahrq.gov/perspectives/perspective/112/lesson-from-the-vas-teamtraining-program (accessed 30 Nov 2016).

26 Passiment M, Sacks H, Huang G. Medical simulation in medical education: results of an AAMC survey. Washington DC: Association of American Medical Colleges, 2011.

27 Rosen KR. The history of medical simulation. J Crit Care 2008:23:157-66.

28 Scott RP, Van Diepen LR, Markert RJ. Simulation Update: a review of simulationbased strategies for healthcare, education and training. SimLearn, Department of Veterans Affairs, June (2010). https://www.simulationinformation.com/sites/default/ files/medsim/news/files/a_review_of_simulation-based_strategies_for_healthcare_ education_and_training_-_june_2010.pdf (accessed 30 Nov 2016).

29 Ziv A, Wolpe PR, Small SD, et al. Simulation-based medical education: an ethical imperative. Simul Healthc 2006;1:252-6.

30 Ozcan YA, Tànfani E, Testi A. A simulation-based modeling framework to deal with clinical pathways. In Proceedings of the Winter Simulation Conference. Winter Simulation Conference. 2011, 1190-201.

31 Maran NJ, Glavin RJ. Low-to high-fidelity simulation-a continuum of medical education? Med Educ 2003;37(Suppl 1):22-8.

32 Kneebone R. Simulation in surgical training: educational issues and practical implications. Med Educ 2003;37:267-77.

33 Goolsby CA, Goodwin TL, Vest RM. Hybrid simulation improves medical student procedural confidence during EM clerkship. Mil Med 2014;179:1223-7.

34 Rudolph JW, Simon R, Raemer DB. Which reality matters? Questions on the path to high engagement in healthcare simulation. Simul Healthc 2007;2:161-3.

35 Bowen HR. Goals: the intended outcomes of higher education. Found Am Higher Educ 1977:2:23-37.

36 Jang $\mathrm{H}$. Supporting students' motivation, engagement, and learning during an uninteresting activity. J Educ Psychol 2008;100:798.

37 Sansone C, Weir C, Harpster L, et al. Once a boring task always a boring task? Interest as a self-regulatory mechanism. J Per Soc Psychol 1992;63:379.

38 Fredricks JA, Blumenfeld PC, Paris AH. School engagement: potential of the concept, state of the evidence. Rev Educ Res 2004;74:59-109.

39 Rudolph JW, Raemer DB, Simon R. Establishing a safe container for learning in simulation: the role of the presimulation briefing. Simul Healthc 2014;9:339-49.

40 Dieckmann P, Gaba D, Rall M. Deepening the theoretical foundations of patient simulation as social practice. Simul Healthc 2007;2:183-93.

41 Pintrich PR, Schrauben B. Students' motivational beliefs and their cognitive engagement in classroom academic tasks. Student Percept Classroom 1992:7:149-83.

42 Hulsman RL, Pranger $\mathrm{S}$, Koot $\mathrm{S}$, et al. How stressful is doctor-patient communication? Physiological and psychological stress of medical students in simulated history taking and bad-news consultations. Int J Psychophysiol 2010;77:26-34

43 Pekrun R. The impact of emotions on learning and achievement: towards a theory of cognitive/motivational mediators. Appl Psychol 1992;41:359-76. 


\section{Simnovate supplement}

44 Pekrun R. Emotions as drivers of learning and cognitive development. In new perspectives on affect and learning technologies. New York: Springer, 2011:23-39.

45 Brydges R, Manzone J, Shanks D, et al. Self regulated learning in simulation based training: a systematic review and meta analysis. Med Educ 2015;49:368-78.

46 Butler DL, Brydges R. Learning in the health professions: what does self-regulation have to do with it? Med Educ 2013:47:1057-9.

47 Dutton D. The art instinct: beauty, pleasure, \& human evolution. USA: Oxford University Press, 2009.

48 Ramachandran VS, Hirstein W. The science of art: a neurological theory of aesthetic experience. J Conscious Stud 1999;6:15-51.

49 Morriss-Kay GM. The evolution of human artistic creativity. J Anat 2010;216:158-76.
50 Silver, M. Why did humans invent music? National Geographic. 24 Aug. 2013. http:// news.nationalgeographic.com/news/2013/08/130824-invention-music-phish-steviewonder-blurred-lines-robin-thicke/ (accessed 30 Nov 2016).

51 Wilson C. I'll be Bach. Slate. 19 May. 2010. http://www.slate.com/articles/arts/ music_box/2010/05/ill_be_bach.single.html (accessed 30 Nov 2016).

52 Boyd B. On the origin of stories. Harvard University Press, 2009.

53 Dutton D. Are we hard-wired for beauty? Ted Radio Hour. 16 April. 2013. http:/l www.npr.org/templates/transcript/transcript.php?storyld=177490162 (accessed 30 Nov 2016).

54 Brown S, Xiaoging $\mathrm{G}$. The neuroscience of beauty —how does the brain appreciate art? 27 Sep. 2011. http://www.scientificamerican.com/article.cfm?id=theneuroscience-of-beauty (accessed 30 Nov 2016). 


\section{Engagement and learning in simulation: recommendations of the Simnovate Engaged Learning Domain Group}

Wayne Choi, Ollivier Dyens, Teresa Chan, Mariles Schijven, Susanne Lajoie, Mary E Mancini, Parvati Dev, Li Fellander-Tsai, Mathieu Ferland, Pamela Kato, James Lau, Michael Montonaro, Joelle Pineau and Rajesh Aggarwal

BMJ STEL 2017 3: S23-S32

doi: 10.1136/bmjstel-2016-000177

Updated information and services can be found at:

http://stel.bmj.com/content/3/Suppl_1/S23

\section{These include:}

References This article cites 38 articles, 2 of which you can access for free at: http://stel.bmj.com/content/3/Suppl_1/S23\#BIBL

Email alerting service

Receive free email alerts when new articles cite this article. Sign up in the box at the top right corner of the online article.

\section{Notes}

To request permissions go to:

http://group.bmj.com/group/rights-licensing/permissions

To order reprints go to:

http://journals.bmj.com/cgi/reprintform

To subscribe to BMJ go to:

http://group.bmj.com/subscribe/ 